\title{
Correction to: On the origin of upper crustal hear-wave anisotropy at Samos Island, Greece
}

\author{
G. Kaviris $^{1}$ (D) I. Spingos ${ }^{1} \cdot$ V. Kapetanidis ${ }^{1} \cdot$ P. Papadimitriou $^{1} \cdot$ N. Voulgaris ${ }^{1}$
}

Published online: 31 May 2021

(c) Institute of Geophysics, Polish Academy of Sciences \& Polish Academy of Sciences 2021

\section{Correction to: Acta Geophysica}

https://doi.org/10.1007/s11600-021-00598-2

The publication of this article unfortunately contained mistakes. Table 1 was missing, you can find it below and the table of Appendix 3 should be Supplemental Information.

The original article has been corrected.

Publisher's Note Springer Nature remains neutral with regard to jurisdictional claims in published maps and institutional affiliations.

The original article can be found online at https://doi.org/10.1007/ s11600-021-00598-2.

\footnotetext{
G. Kaviris

gkaviris@geol.uoa.gr

1 Department of Geology \& Geoenvironment, Section of Geophysics-Geothermics, National and Kapodistrian University of Athens, Athens, Greece
} 
Table 1 Summary of statistics for the shear-wave splitting analysis

\begin{tabular}{lllccc}
\hline Station & Network & $N$ & $\bar{\varphi} \pm \delta \bar{\varphi}\left(\mathrm{N}^{\circ} \mathrm{E}\right)$ & $\bar{t}_{\mathrm{d}} \pm \delta \bar{t}_{\mathrm{d}}(\mathrm{ms})$ & $\bar{t}_{\mathrm{n}} \pm \delta \bar{t}_{\mathrm{n}}\left(\frac{\mathrm{ms}}{\mathrm{km}}\right)$ \\
\hline All stations & All networks & 164 & $77.5 \pm 4.0$ & $95.6 \pm 4.4$ & $6.7 \pm 0.4$ \\
GMLD & KO & 4 & $65.4 \pm 10.0$ & $87.5 \pm 34.2$ & $5.8 \pm 1.2$ \\
KRL1 & HI & 90 & $54.4 \pm 5.0$ & $92.1 \pm 5.8$ & $6.8 \pm 0.6$ \\
SAM2 & HL & 15 & $34.7 \pm 12.7$ & $133.3 \pm 16.2$ & $9.2 \pm 1.9$ \\
SMG & HL & 55 & $107.2 \pm 4.8$ & $91.6 \pm 7.4$ & $5.9 \pm 0.7$ \\
\hline
\end{tabular}

The number of observations $(N)$, mean value and the corresponding standard error of mean $(\delta)$ are included. The table displays values for the polarization direction $(\varphi)$, the time-delay $\left(t_{\mathrm{d}}\right)$ and the normalized time-delay $\left(t_{\mathrm{n}}\right)$. KO: Kandilli Observatory and Earthquake Research Institute (KOERI, https://doi.org/10. 7914/SN/KO), HI: Institute of Engineering Seismology and Earthquake Engineering (ITSAK, https://doi. org/10.7914/SN/HI) and HL: National Observatory of Athens (NOA, https://doi.org/10.7914/SN/HL). 